\title{
Coping Strategies with Stress Urinary Incontinence among Menopausal
}

\section{Women}

\author{
Sara Mamduoh Mohamed, Demonstrator \\ Obstetric and Gynecologic Nursing, Faculty of Nursing, Alexandria University \\ Magda Youssef Helmy, Professor Emeritus \\ Obstetric and Gynecologic Nursing, Faculty of Nursing, Alexandria University \\ Samar Kamal Hafez, Assistant Professor \\ Obstetric and Gynecologic Nursing, Faculty of Nursing, Alexandria University
}

\begin{abstract}
Stress urinary incontinence (SUI) is the most prevalent urinary problem among menopausal women. It has a negative physical and psychological impact on women's quality of life. Consequently Menopausal women with SUI tend to adopt negative or positive coping strategies to improve their quality of life. Objective: Identify coping strategies among menopausal women with urinary stress incontinence. Setting: Urinary incontinence clinic of Main University Hospital Alexandria Regional Center for Women's Health and Development. Subjects: A convenience sample of 200 menopausal women with stress urinary incontinence were recruited in this study. Tools: Three tools were used; I: Basic Data Structured Interview Schedule, II: Urinary Incontinence Interview Schedule: PRAFABQuestionnaire, and III: Revised Jalowiec Coping Scale. Results: One half of study subject (50\%) seldomly used any coping strategies, The self-reliant coping strategy was the most used one while emotive coping strategy was the least used one. Conclusion: Women use problem based coping strategies (Evasive and confronting) in an attempt to positively cop with health problem. Recommendations: Gynecological nurses are advised to attend workshops about the psychological impact of stress incontinence among menopausal women consequently they would be able to gear them towards the appropriate coping strategies.
\end{abstract}

Keywords: Menopausal women; Urinary incontinence; Coping strategies.

\section{Introduction}

Menopause is a significant physical and psychological event for women that mark their transition from the child bearing years to the non-reproductive stage of life. A wide variety of symptoms are reported in midlife women during the menopause transition. Menopause generally occurs around 51 years of age with an age range varying between 40 to 60 years ${ }^{(1)}$.

It is characterized with major changes in the physiology, and hence, in the functions, shape and the form of the woman's body, both physically and psychologically $^{(2)}$. A wide variety of symptoms are reported including hot flashes, night sweats, vaginal dryness, alterations in mood, sleep disturbances, changes in sexuality, cognitive difficulties, somatic complaints and urinary symptoms ${ }^{(1)}$.

Stress urinary incontinence (SUI) is the most prevalent urinary problem among menopausal women. It is defined by National Institute for health and Clinical Excellence (NICE) as the involuntary urine leakage on effort or exertion or on sneezing or coughing ${ }^{(3)}$.

Stress incontinence among menopausal women usually develops due to poor urethral support. The supporting structures of the urethra and bladder neck comprise the muscles of the pelvic floor along with their intact nerve supply and the sub-urethral endopelvic fascia, which is mainly composed of collagen ${ }^{(4)}$. During menopause, collagen turnover demonstrates a difference in collagen remodeling in their 
with stress incontinence compared with continent controls related to progressive collagen attenuation caused by ovarian hormone deficiency that occurs in menopausal transition ${ }^{(5)}$.

Stress incontinence has a negative physical and psychological impact on women's quality of life. So each women attempts to develop effective coping strategies to deal positively with the negatively impact of urinary incontinence on her intimacy and quality of life ${ }^{(6)}$.

Coping strategies are very important to maintain women's identity and perceived competence since UI is often associated with lack of self-control, Menopausal women with SUI use a larger variety of coping strategies to manage their difficulties ${ }^{(7)}$. They follow different measures to solve their problem by cognitively transforming their situation. Under difficult circumstances, they accept the challenge though continuing concentration on the problem in their situation turns out to be a depressing factor and is associated with a lower quality of their life ${ }^{(8)}$. Coping strategies could be in the form of applications that protect menopausal women from UI symptom.

\section{Aim of the Study}

This study aims to identify coping strategies among menopausal women with urinary stress incontinence.

\section{Research Question}

What are coping strategies among menopausal women with urinary stress incontinence?

\section{Materials and Method}

\section{Materials}

Design: A descriptive research design was utilized.

Setting: Urinary incontinence clinic of Main University Hospital Alexandria Regional Center for Women's Health and Development.
Subjects: A convenience of 200 menopausal women.

Tools: Three tools used for data collection:

Tool I: Basic Data Structured Interview Schedule

It has three parts: Part I: Sociodemographic characteristics Part II: Health related data. Part III: Reproductive characteristics of the study subjects.

\section{Tool II: PRAFAB-Questionnaire ${ }^{(9)}$}

To evaluate the severity of urinary incontinence in women. It consists of 20 items distributed among 5 dimensions as follows; Protection (use of pads) 4 items; Amount of urine loss 4 items; Frequency of UI 4 items; Adjustment of behavior due to the symptoms 4 items and Body (or self)image as result of the symptoms of incontinence.

\section{Tool III: Revised Jalowiec Coping Scale $^{(10)}$}

This Scale was adopted and translated to Arabic language by the researcher and used to assess either general coping behavior or coping in specific situations. It comprises 60 items Confrontive $(\mathrm{N}=10)$ Evasive $(\mathrm{N}=13)$ Optimistic $(\mathrm{N}=9)$ Fatalistic $(\mathrm{N}=4)$ Emotive $(\mathrm{N}=5)$ Palliative $(\mathrm{N}=7)$ Support $(\mathrm{N}=5)$ Self-reliant $(\mathrm{N}=7)$.

\section{Method}

The study was conducted according to the following steps:

- Necessary approval was obtained.

- Official letter from the Faculty of Nursing-University of Alexandria was directed to the responsible authorities of the previously mentioned research settings to obtain their permission to conduct the study and collect the necessary data after explanation of research purpose. 
- Tools finalization:

- Tool I was developed by the researcher after an extensive review of recent \& relevant literature.

- Tool II was adopted and translated by the researcher while tool three was adapted, translated and scoring system modified by the researcher.

- Tools' Content Validity and Reliability.

- Tools reliability (internal consistency) was tested by Cronbach's Alpha test and the result was reliable $(r=0.879)$ which is statistically accepted.

- Pilot study:

- A pilot study was carried out on 20 menopausal women who were excluded from the study sample to test the relevance, validity, and clarity of tool as well as the time needed to complete it.

\section{- Collection of data:}

- Each subject was individually interviewed after physician examination which was conducted in total privacy. The duration of each interview ranged between 25 30 minutes depending upon the degree of understanding and response of the interviewee. An average number of interviewee per day ranged from 6-8 from menopausal women with stress urinary incontinence depending upon the number of women in clinic.

- Two days / week were specified for data collection over a period of 4 months, started from the beginning of January till the end of April 2019.

\section{Ethical considerations:}

For each subject an informed oral consent was obtained after explaining the purpose of the study. In addition her anonymity, privacy, freedom to withdraw from the study at any time and confidentiality of her data were all emphasized prior starting the interview.

\section{Statistical Analysis}

Analysis of data was carried out using Statistical Package for Social Sciences (SPSS) version 20. The collected data were categorized, coded, computerized, tabulated and analyzed. Frequency and distribution were used for describing and summarizing categorical data. Cross tabulation with percentages were used to explore relationships between variables. Appropriate tests such as ANOVA, T test and Chi-square at 0.05 level of significance were used.

\section{Results}

Table (1) shows distribution of the study group according to their socio- demographic characteristics. It was found that the studied women's age ranged from 45 to 60 with a mean of $55.41 \pm 7.636$. slightly more than one-half $(52.0 \%)$ of the women aged 55-60 years, while nearly one-quarter $(27.0 \%)$ of them aged less than 50 years.

Almost one-quarter $(24.0 \%)$ of them were illiterate, compared to $28.0 \%$ university or post university graduate. On the other hand, those women with secondary or technical education constituted $34.0 \%$ of them.

Less than two-thirds $(60.0 \%)$ of them were married, while $11.5 \%$ of them were widowed and the rest $(28.5 \%)$ were divorced.

The same table reveals that the majority $(80.0 \%)$ of them were from urban areas, and less than two- thirds $(60.0 \%)$ of them had nuclear families.

Slightly about one-quarter $(26.0 \%)$ of the women reported income insufficiency. On 
the other hand, only $8.0 \%$ of the women mentioned that their income is enough and they can save from it.

Table (2) illustrates distribution of the study group according to their reproductive history. It was noticed that the majority $(92.5 \%)$ of the women had previous history of gravida with a mean of $3.47 \pm 2.168$. Less than three-quarters $(70.8 \%)$ of them has 3 and more pregnancies, and $(60 \%)$ of those women had 3 and more deliveries with a mean of $2.90 \pm 1.717$.

Less than two-thirds (62.7\%) of them had normal deliveries, and less than onequarter $(23.2 \%)$ of them faced complications with their last delivery mainly bleeding as mentioned by $(34.9 \%)$ of them followed by perineal laceration $(23.3 \%)$, vaginal injuries (16.3\%), and lastly, precipitated labor as reported by $7.0 \%$ of them.

Only $(35.7 \%)$ of them had previous abortion, while more than three-quarters $(83.3 \%)$ of them have less than 3 abortions. Additionally, the date of their last delivery was 10 years ago and more as declared by vast majority $(93.0 \%)$ of them .Furthermore, more than two-fifth $(42.2 \%)$ of the women had three to four children followed by (38.4\%) had one to two children while, $2.7 \%$ of them had 9 children and more, with a mean of $3.12 \pm 2.487$ children.

Figure (1) shows distribution of the study group according their severity of stress urinary incontinence (PRAFAB assessment). It shows that about one-half $(49.5 \%)$ of the studied women had moderate degree of stress urinary incontinence, more than onequarter $(27.05 \%)$ of them had severe degree while, $(23.0 \%)$ of them had mild degree of UI.

Figure (2) shows distribution of the study group according to their total score of used coping strategies (revised Jalowiec scale). The figure shows that one-half $(50.0 \%)$ of studied women were seldomly used coping strategies, less than one-half $(48.0 \%)$ of them were sometimes used coping strategies. On the other hand, only $(2.0 \%)$ often used coping strategies.

Table (3) reveals the correlation coefficient between the total mean score of used coping strategies and SUI severity. Positive significant correlation was found between SUI severity among study subjects and their coping strategies such as confronting, fatalistic, emotive and palliative, while coping strategies such as optimism coping strategies were negatively significance correlation with SUI severity.

\section{Discussion}

Among numerous needs and problems menopausal women suffer from; stress urinary incontinence arises as the most important issue affecting the quality of life adversely.

The present study revealed that one-half of menopausal women aged 40 years at onset of SUI. This result in line with Hijaz et al, (2011) ${ }^{(11)}$ who reported that women older than 35 years at had 2.36 higher odds of developing SUI than women younger 35 year and Hannestad et al. (2000) ${ }^{(12)}$ when stratified women with SUI by decade of age found the peak prevalence of SUI $(60 \%)$ occurred in 40-to 49-year-old women in the Norwegian EPINCONT.

Most studies report an increasing prevalence of urinary incontinence with age and on multivariate analysis the menopause has been shown to contribute significantly to its onset especially stress urinary incontinence related to effects of estrogen depletion, parity and gravida on detrusor contraction strength ${ }^{(13)}$.

In addition to the known adverse effects of menopause as an aging process in developing UI, different reproductive characteristics among the study subjects contributed to onset of SUI such as high gravidity and parity among more than twothirds of the study subjects associated with reduced PFM strength, which cause SUI through increased pressure on the PFM and bladder resulting in greater urethral mobility 
leading to urethral sphincter incompetence. Similarly, majority of subjects in a study by Nezam et al. (2011) ${ }^{(14)}$ were more likely to have five pregnancies or more with four deliveries. The difference between gravidity and parity was due to abortion. Also, the present results were in agreement with study findings of Mohamed HG et al. (2018) ${ }^{(15)}$ titled "effect of pelvic floor muscle strengthening-kegel's exercise-on severity of stress urinary incontinence and quality of life among women" who reported that a sizable proportion of studied women go through pregnancy and delivered vaginally for more than three times. Also results of Sensoy et al. (2013) ${ }^{(16)}$ titled "Urinary incontinence in women: prevalence rates risk factors and impact on quality of life " revealed that more than third of the studied patients had 6- 9 gravidas and more than 3 deliveries and documented that the gravid uterus increases the intra-abdominal pressure throughout pregnancy causing weakening of the pelvic floor musculature primarily the levator ani muscle which ultimately can be evidenced by UI.

The current study showed about twothirds of study subjects had normal vaginal delivery and less than one-quarter had complications of last delivery, this may be attributed to the injuries that may be caused in the musculature and innervation in the pelvic floor. This musculature and innervation represents an important factor in the development of the stress urinary incontinence. These results were consistent with those of Nezam et al. (2011) ${ }^{(14)}$ who found more than one half of study subjects had normal vaginal birth and documented that women suffer from SUI due to multiple trauma from childbirth which affects urethral sphincter function.

Assessment of severity urinary incontinence revealed that about one-half of studied women had moderate degree of urinary incontinence and more than onequarter had severe degree. This may be attributed to the fact that some women with SUI of a mild nature do not feel that treatment of the condition is warranted, others are embarrassed to speak with a health care provider about their condition or fear that treatment requires surgery treatment which in turn resulted in gradual increase in the severity of SUI often to the point of causing women to stop doing their normal activities ${ }^{(14)}$. Similar results were observed by Singh et al. $(2015)^{(17)}$ who noted that half of study subjects have moderate urinary incontinence. Orhan $\mathrm{C}$ et al. $(2019)^{(18)}$ studied the "Effect of incontinence severity on symptom distress, quality of life, and pelvic floor muscle function in Turkish women with urinary incontinence" reported that two-thirds of study subjects had mild and moderate degrees urinary incontinence. On the other hand, Kobashi $(2011)^{(19)}$ concluded that stress urinary incontinence generally considered majority of studied women were mild degree who only experience light leakage during vigorous activity such as playing sports or exercising, or while sneezing, laughing and coughing.

In relation to coping strategies, the current study shows that one- half of studied women were seldomly use coping strategies. This result is expected where slightly more than one-third of the studied women mentioned that urinary incontinence does not affect their daily activities and more than one half of them aged 55 and more and usually did not attach much importance to UI due to perceiving it as a normal consequence of aging. These findings were not in harmony with those of Potdar \& Shinde $(2015)^{(20)}$ study titled Psychological Problems and Coping Strategies Adopted By postmenopausal Women they found $76 \%$ post-menopausal women's were using coping strategy often.

Correlation between severity of stress urinary incontinence and used coping strategie Statistically significant correlations were found between SUI severity and evasive, supportive and self -reliant coping strategies among current study these results were not in harmony with findings of 
Bosworth et al. (2003) ${ }^{(9)}$ study who found avoidance and seeking social support as evasive and supportive coping strategies have significant relations with menopausal stress and Senra et al. $(2015)^{(22)}$ who found women used expression of feelings as supportive coping strategies according to degree of urine loss as moderate versus severe loss of urine. Women who reported sever urine loss used more expression of feelings as coping strategy to deal with the UI positive correlation.

The current study significantly clarified that coping strategies were used by menopausal women in an attempt to cope with of SUI symptoms and improve their quality of life. Gynecological nurses should be alert and sensitive to this issue consequently Health problems of the menopausal women should be underlined and addressed to some extent in the government's policy.

\section{Conclusion}

In the light of the present study results, it can be concluded that menopausal women seldom used problem based coping strategies (Evasive and confronting) in an attempt to positively cope with their health problem and mostly useful coping strategies according to ranking and positive statistically significant relation were found between UI severity mean scores and confronting, fatalistic, emotive and lastly, the total score of coping strategies. One the other hand negative statistically significant relation was found between UI severity mean scores and optimistic coping strategies.

\section{Recommendations}

Based on the findings of this study, the following recommendations were suggested:

- Gynecological nurses are advised to attend workshops as like-wise about the psychological impact of stress incontinence among menopausal women that enables them to gear women toward the appropriate coping strategies

- Dissemination simple information guide (booklet ) for gynecological nurses about improvement and prevention SUI and other problems related to PFM dysfunction through education about Kegel exercises is needed.

- Plan an individualized care to patients needs to empower them to cope with their condition and adopt healthy behavior

- Influencing health education policy to promote health and adopt a menopause lifestyle requires alternative strategies, including health training programs with community-based interventions.

- Mass media sector should be utilized in dissemination simple information about awareness of menopausal women about prevention, management, help seeking behavior and how to cope with SUI and other health problem associated to menopause.

- Educating physicians and the public about the effect of different coping strategies especially effective coping strategies toward UI management may assist women to seek and receive more timely care for incontinence symptoms through health promotion programs. 
Table (1): Distribution of the studied women according to their socio-demographic characteristics

\begin{tabular}{|c|c|c|}
\hline \multirow[t]{2}{*}{ Women's characteristics } & \multicolumn{2}{|c|}{$\begin{array}{l}\text { Total } \\
\mathbf{N}=\mathbf{2 0 0}\end{array}$} \\
\hline & No & $\%$ \\
\hline \multicolumn{3}{|l|}{ Age (years) } \\
\hline $.45-$ & 54 & 27.0 \\
\hline $.50-$ & 42 & 21.0 \\
\hline$\cdot 55-60$ & 104 & 52.0 \\
\hline Mean \pm SD & \multicolumn{2}{|c|}{$55.41 \pm 7.636$} \\
\hline \multicolumn{3}{|l|}{ Level of education } \\
\hline - Illiterate & 48 & 24.0 \\
\hline - Read \& write & 19 & 9.5 \\
\hline - Basic education & 9 & 4.5 \\
\hline - Secondary/ technical education & 68 & 34.0 \\
\hline - University / Post university education & 56 & 28.0 \\
\hline Marital status & \multicolumn{2}{|c|}{$\mathrm{N}=200$} \\
\hline - Married & 120 & 60.0 \\
\hline - Widowed & 23 & 11.5 \\
\hline - Divorced & 57 & 28.5 \\
\hline \multicolumn{3}{|l|}{ Type of family } \\
\hline - Nuclear & 120 & 60.0 \\
\hline - Extended & 80 & 40.0 \\
\hline \multicolumn{3}{|l|}{ Income sufficiency } \\
\hline - Enough and save & 16 & 8.0 \\
\hline - Hardly enough & 132 & 66.0 \\
\hline - Not enough & 52 & 26.0 \\
\hline
\end{tabular}


Table (2): Distribution of the studied women according to their obstetrical history

\begin{tabular}{|c|c|c|}
\hline \multirow[t]{2}{*}{ Obstetrical data } & \multicolumn{2}{|c|}{$\begin{array}{c}\text { Total } \\
\mathrm{N}=200\end{array}$} \\
\hline & No & $\%$ \\
\hline Number of gravida & \multicolumn{2}{|c|}{$\mathrm{N}=185$} \\
\hline.$<3$ & 54 & 29.2 \\
\hline - 3 and more & 131 & 70.8 \\
\hline Mean \pm SD & \multicolumn{2}{|c|}{$3.47 \pm 2.168$} \\
\hline \multicolumn{3}{|l|}{ Number of parities } \\
\hline.$<3$ & 74 & 40.0 \\
\hline . 3 and more & 111 & 60.0 \\
\hline Mean \pm SD & \multicolumn{2}{|c|}{$2.90 \pm 1.717$} \\
\hline \multicolumn{3}{|l|}{ Type of last delivery } \\
\hline - Normal & 116 & 62.7 \\
\hline - Normal with episiotomy & 21 & 11.4 \\
\hline - Caesarian Section & 48 & 25.9 \\
\hline Number of abortions & \multicolumn{2}{|c|}{$\mathrm{N}=66$} \\
\hline.$<3$ & 55 & 83.3 \\
\hline - 3 and more & 11 & 16.7 \\
\hline Mean \pm SD & \multicolumn{2}{|c|}{$1.57 \pm 0.119$} \\
\hline Mean \pm SD & \multicolumn{2}{|c|}{$3.12 \pm 2.487$} \\
\hline
\end{tabular}

\section{Distribution of the studied women according 1} thier severity of urinary incontinence

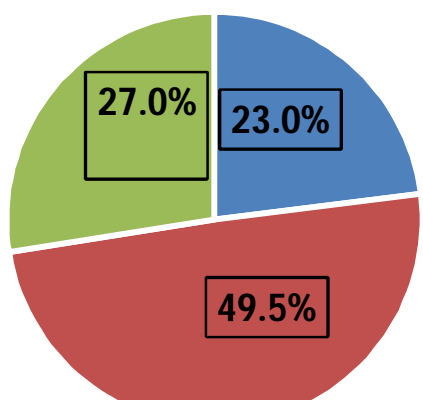

Figure (1): Distribution of studied women according their severity of urinary incontinence (PRAFAB assessment) $n=200$ 


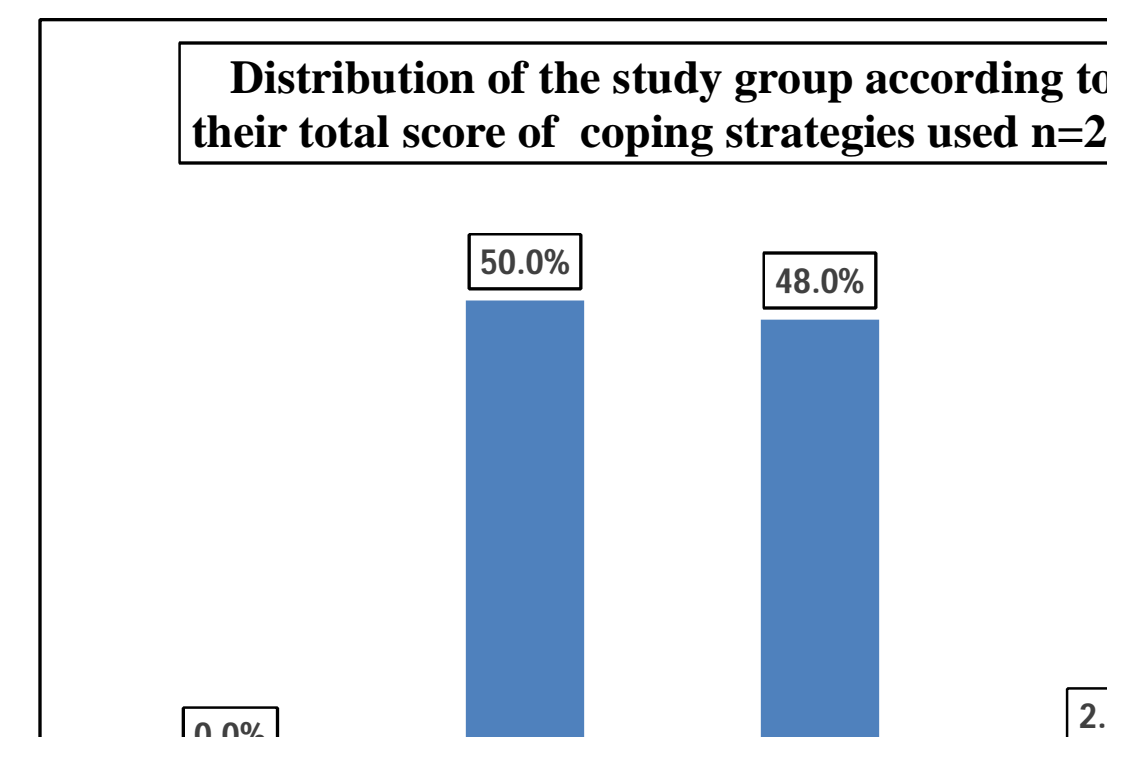

Figure (2): Distribution of the study group according to their total score of the used coping strategies (Revised Jalowiec Scale)

Table (3): The correlation coefficient between the total mean score of used coping strategies and SUI severity

\begin{tabular}{|l|c|c||}
\hline Statistical Test Pearson's r & $\begin{array}{c}\text { Correlation } \\
\text { Coefficient }\end{array}$ & Significance \\
\hline -Confronting & 0.228 & $0.001^{*}$ \\
\hline -Evasive & 0.046 & 0.521 \\
\hline -Optimism & -0.229 & $0.001^{*}$ \\
\hline -Fatalistic & 0.239 & $0.001^{*}$ \\
\hline -Emotive & 0.344 & $0.000^{*}$ \\
\hline -Palliative & 0.204 & $0.004^{*}$ \\
\hline -Supportive & 0.095 & 0.183 \\
\hline -Self-reliance & -0.022 & 0.760 \\
\hline Total coping strategies used & 0.196 & $0.026^{*}$ \\
\hline * Statistically significant at $\leq 0.05$ & & \\
\hline
\end{tabular}




\section{References}

1. Digumarti L, Agarwal N, Vaze N, Shah R, Malik S. Clinical practice guidelines on menopause: An executive summary and recommendations. Journal of Mid-life Health.2013;4(2) :78-90

2. Santoro N, Epperson C, Mathews S, Menopausal Symptoms and Their Management, Elsevier.2015;44: 497-515

3. Townsend M \& Lajous M, Campos R. Risk factors for urinary incontinence among postmenopausal Mexican women. International Urogynecological Association. 2016; 28: 769-776.

4. Singh S, Herwijnen I, Phillips C. The management of lower urogenital changes in the menopause. Menopause International 2013; 19(2):77-81.

5. Leaver RB. International Journal of Urological Nursing. London: Wiley; 2012

6. Nygaard I, Shaw J, Bardsley T, Egger MJ. Lifetime physical activity and pelvic organ prolapse in middle-aged women. Obstet Gynecol J 2014; 210:477 -512.

7. Segedi LM, Segedi D, Parezanovicllic K (2011) Quality of life in women with urinary incontinence. Medical Glas Zenica 2011; 8(2): 237-242.

8. Buettner, H.M. et al. Kinetics of microtubule catastrophe assessed by robabilistic analysis. Biophys. J. 1995; 69: 796-802.

9. Hendriks E, Bernards A. The minimal important change of the PRAFAP questionair in women with stress urinary incontinence results from aprospective cohort study. Neurourol Urodyn 2008; 27:379-87.

10. Jalawiec A, Murphy S, Powers MJ. Psychometric assessment of Jalawiec coping scale. Nurs Res 1984; 33:157-61.

11. Hijaz A \& Sadeghi Z \& Byrne L\& Tsung Hou J \& Daneshgari F. Advanced maternal age as a risk factor for stress urinary incontinence: a review of the literature. Int Urogynecol J. 2012; 23:395-401. DOI 10.1007/s00192-011-1562-5.

12. W. Stuart Reynolds \& Roger R. \& David F. Penson. Epidemiology of Stress Urinary Incontinence in Women. Curr Urol Rep (2011) 12:370-376 DOI 10.1007/s11934011-0206-0

13. Alayne D. Holly E. Eggers p, John W. Kusek. Prevalence and Trends of Urinary Incontinence in Adults in the United States, 2001 to 2008 Urol. 2011 Aug; 186(2): 589593. Doi: 10.1016/j.juro.2011.03.114
14. Nezam A. Effect of Kegel exercise on strength of pelvic floor muscles among women with stress urinary incontinence. Faculty of Nursing, Alexandria University, 2011.

15. Mohamed H, Hafez S, Basyouni N. effect of pelvic floor muscle strengthening-kegel's exercise-on severity of stress urinary incontinence and quality of life among women. International Journal of Novel Research in Healthcare and Nursing 2018; 5(3): 421-438

16. Sensoy N, Dogan N, Ozek B, Karaaslan L . Urinary incontinence in women: prevalence rates risk factors and impact on quality of life. Pak Journal of Medical Science 2013. 29.(3): 818-822

17. Singh N and Goel N. Prevalence and Risk Factors of Urinary Incontinence Among Women Delivering in a Tertiary Care Center of Northern India. Obstetrics \& Gynecology International Journal. 2015 3(4). DOI: 10.15406/ogij.2015.03.00087

18. ORHAN C, OZGUL $S$ and BARAN $M$. The Effect of Incontinence Severity on Symptom Distress, Quality of Life, and Pelvic Floor Muscle Function in Turkish Women with Urinary Incontinence. Gynecology Obstetrics \& Reproductive Medicine journal. 2019;25 DOI:10.21613/GORM.2018.911.

19. Kobashi K. Physician / healthcare provider pocket guide: stress urinary incontinence. 2011. Available at URL: http://www.Urologyhealth.org/SUI/ docum ents/_pdf/AUAF SUI_PocketGuide.pdf. Retrieved on: 21 July 2011.

20. Potdar N, Shinde M. Psychological Problems and Coping Strategies Adopted By Post Menopausal Women. International Journal of Science and Research, 2015; 3(2): 2319-7064.

21. Bosworth H, Bastian L, Rimer B. coping styles and personality domains related to menopausal stress. Women's Health Issues 2003; 13:32-38.

22. Senra C Pereira M. Quality of life in women with urinary incontinence. Rev. Assoc. Med. Bras Apr. 2015(2); 61. 